\title{
Direct Investment Liberalization, Commodity Trade, and Income Distribution: What Can the WTO Do?
}

\author{
Kar-yiu Wong \\ University of Washington
}

April 2001 


\begin{abstract}
This paper analyzes a model of two-way movement of physical capital, and examines the effects of direct investment liberalization on resource allocation, income distribution, and commodity trade. If either country or both countries liberalizes investment under exogenously given commodity prices, some factor owners in a country will gain but some others will lose. If capital movement affects commodity prices, there are cases in which all factor owners in a country are better off after multilateral investment liberalization. In these cases, it will be much easier for the home country to sign an agreement liberalizing investment flows.
\end{abstract}

This paper was presented at the workshop on "WTO and World Trade," Seattle, December 4, 1999 (http://faculty.washington.edu/karyiu/) and at the workshop on WTO at University of California, Santa Cruz, May 12, 2000. Thanks are due to Theo Eicher and the participants of the two workshops for comments. Copies of this paper can be obtained online at http://faculty.washington.edu/karyiu/.

(c) Kar-yiu Wong. 


\section{Introduction}

Previous multilateral trade talks organized by the General Agreement on Tariffs and Trade (GATT) focused nearly exclusively on trade liberalization and reduction of trade restrictions. Very little efforts had been made on liberalizing direct investment and the movement of capital (physical or financial) among countries. Things changed toward the end of the Uruguay round, when countries turned their attention to direct investment across country borders. At the end of the round, countries signed an agreement restricting trade related investment measures (TRIMs). With the conclusion of the GATT and the establishment of the World Trade Organization (WTO), the agreement on TRIMs prohibits WTO member countries from applying "any TRIM that is inconsistent with the provisions of Article III (obligation of national treatment) or Article XI (no quantitative restrictions) of GATT 1994."

Despite these efforts, the agreement on TRIMs is incomplete and flawed. First, it prohibits certain investment measures only in the context of the GATT articles. Second, there are many articles of GATT that can be used as loopholes for countries to hide or disguise many types of TRIMs. ${ }^{1}$ Third, Article $\mathrm{V}$ of the agreement gives countries substantial transition period before the agreement is fully implemented: two years for developed countries, five years for developing countries and seven years for least developed countries. $^{2}$ In fact, many developing countries are currently applying to extend the transitional period. ${ }^{3}$

Nevertheless, it is clear that countries are paying increasing attention to issues related to cross-country investment. For example, the Organization for Economic Co-operation and Development (OECD) member countries began in 1995 multilateral negotiations on issues related to investment, aiming at concluding a comprehensive multilateral agreement on investment (MAI).

\footnotetext{
${ }^{1}$ For example, Article IV of the agreement permits developing countries to deviate from the agreement when experiencing balance-of-payment difficulties, in accordance with Article XVIII of the GATT.

${ }^{2}$ See Edwards and Lester (1997) and Daly (1988) for more details.

${ }^{3}$ Many countries are applying to the WTO for extension of the transitional period before implementing the full agreement on TRIMs agreement. See the following web site for links — http://faculty.washington.edu/karyiu/WTO/links.htm.
} 
With the increasing attention to investment issues and with the increasing importance of investment flows internationally, people are urging the WTO to reach a new agreement on TRIMs. ${ }^{4}$ Thus, after more than forty years' efforts and achievement on trade liberalization, time has come to consider doing something about trade related investment measures. There is a belief that new multilateral agreements on TRIMs can be reached in the near future.

The objective of this paper is to examine the effects of multilateral investment liberalization on resource allocation, commodity trade, and income distribution. The effects on income distribution are especially important because whether a country has an incentive to sign an agreement on TRIMs depends on how much support it can get domestically, which in turn depends on how various individuals in the economy may be affected by such an agreement. Ideally, a country will have no hesitation to sign such an agreement if the agreement Pareto improves the economy. While Pareto dominating policies are rare, it is the purpose of this paper to search for a multilateral investment liberalizing policy that making all individuals in a country better off.

Analyzing multilateral investment liberalizing is uncommon in the literature. Most papers focus on analyzing the restrictions imposed by one single country on investment from abroad. ${ }^{5}$ For the purpose of this paper, we need a model that can be used to analyze the investment liberalization policies of two countries at the same time. For the same reason, the model should allow movement of capital in both directions, so that the two countries under consideration play host to investment from the other country. Such a two-way flow of capital has been analyzed in the literature, but none of the available models has been used to address the issues we are looking at in the present paper.

In addition to examining the impacts on income distribution, the model is used to investigate how multilateral investment liberalization may affect commodity trade. In the present model, we consider a simple case in which free trade in goods is allowed, while the investment restrictions imposed by the countries are being lessened. Because changes in the investment policies of the countries may affect the countries' income and production, the volumes of trade may be affected. Whether capital movement may diminish or

\footnotetext{
${ }^{4}$ See, for example, Edwards and Lester (1997) and Graham (1996).

${ }^{5}$ For a recent survey on effects of investment liberalization, mainly by one single country, see Wong (1995, Chapters 11 and 13).
} 
augment commodity trade is what we want to find out.

We discover that with no monopoly power in trade, both countries can expect to find both gainers and losers in the economy as investment is liberalized by either one or both countries, although who gain or who lose is not certain, depending on, among other things, how capital movements affect factor prices in the two countries. If the countries have certain monopoly power in trade so that commodity prices are affected by capital movement, there may exist some investment liberalization policies that benefit everyone in a country.

The rest of the paper is organized as follows. Section 2 describes the model. In particular, we use sector-specific capital to introduce two-way flows of capital. Section 3 examines free trade in goods and movement of capital. Section 4 investigates the effects of unilateral and multilateral investment liberalization and examines how it may affect resource allocation and income distribution. The case considered in Sections 2 to 4 is one in which both countries have no monopoly power in trade. Section 5 relaxes the latter assumption and investigates how investment liberalization may affect world prices of commodities, resource allocation, and income distribution. In particular, it will find out whether investment liberalization can benefit everyone in the home country. The last section concludes.

\section{The Model: Sector-Specific Capital}

For the purpose of this paper, we need a model that allows two-way movements of capital. We choose the specific-capital model, sometimes called the Ricardo-Viner model, with two types of capital, each of which is specific to a sector. ${ }^{6}$ This model has been used in many papers and are well known to trade theorists. ${ }^{7}$ As Batra and Ramachandran (1980) argue, sector specificity of capital is a reasonable assumption for analyzing international

\footnotetext{
${ }^{6}$ There are other models of cross-hauling of direct investment. For example, Chan and Wong (1998) considers a model in which intraindustry trade and intraindustry investment could exist between two countries.

${ }^{7}$ See Jones (1971) and Wong (1995, Chapter 2) for a discussion of specific-factor models and the references for some of the work using specific-factor models. These models have been used to analyze various issues related to international factor mobility; for example, Batra and Ramachandran (1980), Caves (1982), Brecher and Feentra (1983), Jones, Neary and Ruane (1983), and Srinivasan (1983). However, none of these papers have addressed the issues currently considered in this paper.
} 
capital movement because international investment involves more than transfer of capital. Technological knowledge, managerial know-how, and marketing techniques are embodied in international investment and specific to the sector. Caves (1982) also makes a similar point: international investment involves the transfer of a bundle of sector-specific assets. This approach has also been used in other papers such as Brecher and Findlay (1983) and Srinivasan (1983) to investigate various issues about international capital movement.

This paper considers two economies called home and foreign. In each of these two economies, there are two competitive sectors labeled 1 and 2, and two types of capital labeled K-capital and B-capital, which are specific to sectors 1 and 2, respectively. Labor is perfectly mobile between the two sectors; thus the wage rates in the two sectors are equalized in equilibrium. Prices are perfectly flexible, guaranteeing full employment of factors. In terms of two-way capital flows, we assume that under the conditions specified in this paper, home is a source country for K-capital and a host country for B-capital. Suppose that the home country imposes an income tax of specific rate $1>\tau \geq 0$ on foreign B-capital working in the economy, while the foreign country imposes an income tax of specific rate $1>t^{*} \geq 0$ on the home $\mathrm{K}$ capital working in its economy. ${ }^{8}$ Throughout the present paper, $\tau$ and $t^{*}$ are treated as policy parameters.

This section derives the properties of the home economy. Denote the two sectoral production functions by:

$$
\begin{aligned}
& Q_{1}=F\left(K, L_{1}\right) \\
& Q_{2}=G\left(B, L_{2}\right),
\end{aligned}
$$

where $Q_{i}$ is the output of sector $i, L_{i}$ is the labor input in sector $i, i=1$, 2 , and $K$ and $B$ are the inputs of the two types of capital. Each production function is concave, strictly increasing, at least twice differentiable, and linearly homogeneous. More specifically, the production functions are assumed to satisfy

$$
\begin{gathered}
F_{j}, G_{j}>0 ; F_{j j}, G_{j j}<0, F_{K L}, G_{B L}>0, \text { and } \\
F_{L L} F_{K K}-F_{K L}^{2}=G_{L L} G_{B B}-G_{B L}^{2}=0,
\end{gathered}
$$

\footnotetext{
${ }^{8}$ For the issues analyzed in the present model, we consider only the cases of income taxes, not subsidies.
} 
where $j=K, B, L$, and subscripts of the production functions denote partial derivatives.

The home economy is endowed with given amounts of the factors, $\bar{L}, \bar{K}$, and $\bar{B}$. Assume that an amount $k$ of domestic K-capital flows out of sector 1 (to the foreign economy) and that an amount $b^{*}$ of foreign B-capital flows into sector 2. Full employment of the factors is described by:

$$
\begin{aligned}
L_{1}+L_{2} & =\bar{L} \\
K & =\bar{K}-k \\
B & =\bar{B}+b^{*} .
\end{aligned}
$$

Choosing good 2 as the numeraire, define $p$ as the domestic relative price of good 1. Denote the domestic wage rate by $w$, rental rate of the K-type capital by $r$, and the rental rate of the B-type capital by $\gamma$. Cost minimization by the firms implies that the factor prices are given by

$$
\begin{aligned}
w & =p F_{L}\left(\bar{K}-k, L_{1}\right) \\
r & =p F_{K}\left(\bar{K}-k, L_{1}\right) \\
\gamma & =G_{B}\left(\bar{B}+b^{*}, \bar{L}-L_{1}\right) .
\end{aligned}
$$

Note that condition (4a) refers to sector 1 , but perfect mobility of labor equalizes the wage rate in both sectors; i.e.,

$$
p F_{L}\left(\bar{K}-k, L_{1}\right)=G_{L}\left(\bar{B}+b^{*}, \bar{L}-L_{1}\right) .
$$

Condition (5) can be used to solve for the equilibrium of labor employment in sector $1, L_{1}$, in terms of $p, k$, and $b^{*}$, i.e., $L_{1}=L_{1}\left(p, k, b^{*}\right)$. Differentiate condition (5) and rearrange terms to yield the following effects on the employment of labor in sector 1 :

$$
\begin{aligned}
& \frac{\partial L_{1}}{\partial p}=-\frac{F_{L}}{\Phi}>0 \\
& \frac{\partial L_{1}}{\partial k}=\frac{p F_{K L}}{\Phi}<0 \\
& \frac{\partial L_{1}}{\partial b^{*}}=\frac{G_{B L}}{\Phi}<0,
\end{aligned}
$$

where $\Phi=p F_{L L}+G_{L L}<0$. It is well known that with three factors and two sectors, even if commodity prices are fixed, factor prices depend on the 
amounts of factors available in the economy. With factor endowments given, factor prices can be expressed as reduced functions of the relative commodity price and the movements of the two types of capital. Differentiate both sides of (4a) to (4c) and rearrange terms, making use of $L_{1}=L_{1}\left(k, b^{*} ; p\right)$, to give the derivatives of the factor price functions:

$$
\begin{aligned}
w_{p} & \equiv \frac{\partial w}{\partial p}=\frac{F_{L} G_{L L}}{\Phi}>0 \\
r_{p} & \equiv \frac{\partial r}{\partial p}=F_{K}-\frac{p F_{K L} F_{L}}{\Phi}>0 \\
\gamma_{p} & \equiv \frac{\partial \gamma}{\partial p}=\frac{F_{L} G_{B L}}{\Phi}<0 \\
w_{k} & \equiv \frac{\partial w}{\partial k}=-\frac{p F_{K L} G_{L L}}{\Phi}<0 \\
r_{k} & \equiv \frac{\partial r}{\partial k}=-\frac{p F_{K K} G_{L L}}{\Phi}>0 \\
\gamma_{k} & \equiv \frac{\partial \gamma}{\partial k}=-\frac{p F_{K L} G_{B L}}{\Phi}>0 \\
w_{b^{*}} & \equiv \frac{\partial w}{\partial b^{*}}=\frac{p F_{L L} G_{B L}}{\Phi}>0 \\
r_{b^{*}} & \equiv \frac{\partial r}{\partial b^{*}}=\frac{p F_{K L} G_{B L}}{\Phi}<0 \\
\gamma_{b^{*}} & \equiv \frac{\partial \gamma}{\partial b^{*}}=\frac{p F_{L L} G_{B B}}{\Phi}<0 .
\end{aligned}
$$

The derivatives in conditions (7a) to (7i) are intuitive. For example, an increase in $k$, meaning more outflow of home K-capital, will lower the marginal product of labor in that sector, driving some labor to sector 2, making the wage rate lower and the marginal product of B-capital higher than before. At the same time the marginal product of K-capital is higher with less K-capital in sector 1. It is interesting to note further that the movement of the two types of capital have opposite effects on the factor prices. Conditions (7h) and (7f) imply that $r_{b^{*}}=-\gamma_{k}$.

Lemma 1 For the home economy, the following conditions hold:

$$
\frac{r_{k}}{r_{b^{*}}}=\frac{\gamma_{k}}{\gamma_{b^{*}}}=\frac{w_{k}}{w_{b^{*}}}=\rho
$$


where $\rho$ is a negative number.

Proof. The proof is given in two steps. First, using the derivatives of factor prices derived earlier, we have

$$
\frac{r_{k}}{r_{b^{*}}}-\frac{w_{k}}{w_{b^{*}}}=-\frac{F_{K K} G_{L L}}{F_{K L} G_{B L}}+\frac{F_{K L} G_{L L}}{F_{L L} G_{B L}}=0
$$

where condition (2) has been used. Similarly, we have

$$
\frac{\gamma_{k}}{\gamma_{b^{*}}}-\frac{w_{k}}{w_{b^{*}}}=-\frac{G_{B L} F_{K L}}{F_{L L} G_{B B}}+\frac{F_{K L} G_{L L}}{F_{L L} G_{B L}}=0 .
$$

Conditions (9) and (10) give the first two equalities in (8). The last equality in $(8)$ comes from conditions $(7 \mathrm{~d})$ to $(7 \mathrm{i})$.

Lemma 1 implies that given commodity prices and for all factor prices, the marginal effect of K-capital movement on each of them is equal to a nagative constant multiplied by the marginal effect of B-capital movement on the same factor price. It further implies that movements of the two types of capital have opposite effects on each of the factor prices. Note that the results stated in the lemma requires constant commodity prices.

The above analysis can be extended to the foreign country. With the assumed movemet of the two types of capital, the foreign rental rates of capital can also be expressed as functions of its domestic price ratio and the capital flows: $r^{*}=r^{*}\left(p^{*}, k, b^{*}\right)$ and $\gamma^{*}=\gamma^{*}\left(p^{*}, k, b^{*}\right)$, where an asterisk is used to denote a foreign variable. The same technique can be used to show, for example, $r_{p^{*}}^{*}>0, r_{k}^{*}<0, r_{b^{*}}^{*}>0, \gamma_{p^{*}}^{*}<0, \gamma_{k}^{*}<0$, and $\gamma_{b^{*}}^{*}>0$. Furthermore, a condition analogous to (8) holds.

In the presence of capital mobility, denote the GDP function of the economy by $g\left(p, \bar{K}-k, \bar{B}+b^{*}\right)$, which is differentiable, convex in $p$, and concave in $(K, B)$. Furthermore, the derivatives of the function are equal to ${ }^{9}$

$$
\begin{aligned}
g_{p} & =Q_{1} \\
g_{K} & =-g_{k}=r \\
g_{B} & =g_{b^{*}}=\gamma .
\end{aligned}
$$

\footnotetext{
${ }^{9}$ For the properties of the GDP function, see Wong (1995).
} 
Using the derivatives of the GDP function, it is easy to confirm an earlier result given in $(7 \mathrm{~h})$ and $(7 \mathrm{f})$ :

$$
-\gamma_{k}=\gamma_{K}=\frac{\partial^{2} g}{\partial K \partial B}=r_{B}=r_{b^{*}}
$$

The effects of capital movement on the output of good 1 are:

$$
\begin{aligned}
\frac{\partial Q_{1}}{\partial k} & =-F_{K}+F_{L} \frac{\partial L_{1}}{\partial k}<0 \\
\frac{\partial Q_{1}}{\partial b^{*}} & =F_{L} \frac{\partial L_{1}}{\partial b^{*}}<0 .
\end{aligned}
$$

The national income of the home country, which is a better measure of the welfare of the economy, is equal to

$$
Y\left(p, k, b^{*}, \tau, t^{*}\right)=g\left(p, \bar{K}-k, \bar{B}+b^{*}\right)+\left(1-t^{*}\right) r^{*} k-(1-\tau) \gamma b^{*} .
$$

The derivatives of the national income function are

$$
\begin{aligned}
Y_{p} & =Q_{1}+\left(1-t^{*}\right) r_{p}^{*} k-(1-\tau) \gamma_{p} b^{*}>0 \\
Y_{k} & =\left(1-t^{*}\right) r_{k}^{*} k-(1-\tau) \gamma_{k} b^{*}<0 \\
Y_{b^{*}} & =\tau \gamma+\left(1-t^{*}\right) r_{b^{*}}^{*} k-(1-\tau) \gamma_{b^{*}} b^{*}>0 \\
Y_{\tau} & =\gamma b^{*}>0 \\
Y_{t^{*}} & =-r^{*} k<0,
\end{aligned}
$$

where the signs are based on the assumed directions of movements of capital and conditions (11). Note that an increase in $p$ improves the national income of the economy. This is partly due to the production effect, and partly due to the income effect: an increase in $p$ raises the income of home K-capital working abroad but lowers the payment to foreign capital working in the economy.

Denote the consumption demand for good 1 by $C_{1}(p, Y)$. Let $m \equiv \partial C_{1} / \partial Y$, where $m p$ is the marginal propensity to consume good 1. Assuming that both goods are normal, $1>m p>0$. The export supply function of good 1 is defined as

$$
E\left(p, k, b^{*}, \tau, t^{*}\right)=Q_{1}\left(p, k, b^{*}\right)-C_{1}\left(p, Y\left(p, k, b^{*}, \tau, t^{*}\right)\right) .
$$


The derivatives of the export supply function are

$$
\begin{aligned}
E_{p} & =\frac{\partial Q_{1}}{\partial p}-\left[\frac{\partial C_{1}}{\partial p}+m Y_{p}\right] \\
E_{k} & =\frac{\partial Q_{1}}{\partial k}-m Y_{k} \\
E_{b^{*}} & =\frac{\partial Q_{1}}{\partial b^{*}}-m Y_{b^{*}}<0 \\
E_{\tau} & =-m Y_{\tau}<0 \\
E_{t^{*}} & =-m Y_{t^{*}}>0 .
\end{aligned}
$$

In general, the signs of $E_{p}$ and $E_{k}$ are ambiguous. At low export levels and capital movements, generally the offer curve of the economy is positively sloped, so that $E_{p}>0$. If the levels of movements of both types of capital are low, $Y_{k}$ is small and $E_{k}<0$.

\section{Free Trade with Cross-hauling Investment}

We now say something more about the world markets. Free trade exists between the economies, while both governments impose non-prohibitive income taxes on investment from the other country. The asymmetry between the degrees of restrictions on commodity trade and capital flows is to capture the fact that previous trade talks have achieved liberalization of commodity trade but has done little in terms of direct investment. We assume that home exports good $1 .{ }^{10}$

In this and the next sections, we consider the case in which capital movements and income taxes do not affect the prevailing commodity prices faced by both countries; this assumption will be relaxed later. Thus for the time being we can denote the relative price of good 1 by $\bar{p}$.

Exogeneity of $p$ can be justified as follows. Both countries are small, trading with the rest of world and facing given commodity prices. Capital flows between the countries could affect factor prices because capital owners have to pay costs for financing such capital movement. These costs may exist

\footnotetext{
${ }^{10}$ This means that home exports good 1 while the capital specific to that sector flows out of the economy. This seems to be consistent with what is commonly observed where a sector with comparative advantage usually sends out capital.
} 
in the form of risk premium as the risks associated with more movement of K-capital go up.

In the presence of the income tax rates imposed by the two governments, the equilibrium of international capital movement is described by the following two conditions:

$$
\begin{aligned}
r\left(\bar{p}, k, b^{*}\right) & =\left(1-t^{*}\right) r^{*}\left(\bar{p}, k, b^{*}\right) \\
(1-\tau) \gamma\left(\bar{p}, k, b^{*}\right) & =\gamma^{*}\left(\bar{p}, k, b^{*}\right) .
\end{aligned}
$$

For simplicity the dependence of the factor price functions on factor endowments is not shown. For the present analysis, it is more convenient to define the following two functions:

$$
\begin{aligned}
\phi\left(k, b^{*}, t^{*} ; \bar{p}\right) & \equiv\left(1-t^{*}\right) r^{*}\left(\bar{p}, k, b^{*}\right)-r\left(\bar{p}, k, b^{*}\right) \\
\theta\left(k, b^{*}, \tau ; \bar{p}\right) & \equiv(1-\tau) \gamma\left(\bar{p}, k, b^{*}\right)-\gamma^{*}\left(\bar{p}, k, b^{*}\right) .
\end{aligned}
$$

These two functions represent the gaps between the after-tax incomes for capitalists in the two countries. For example, if $\phi\left(k, b^{*}, t^{*} ; \bar{p}\right)>0$, then the after-tax income of K-capital in the foreign country is higher than that in the home country. Using these two functions, the equilibrium conditions (14a) and $(14 \mathrm{~b})$ can be expressed as

$$
\begin{aligned}
\phi\left(k, b^{*}, t^{*} ; \bar{p}\right) & =0 \\
\theta\left(k, b^{*}, \tau ; \bar{p}\right) & =0 .
\end{aligned}
$$

Differentiating both sides of equation (15a) and rearranging the terms, we get

$$
\begin{aligned}
\phi_{k} & =\left(1-t^{*}\right) r_{k}^{*}-r_{k}<0 \\
\phi_{b^{*}} & =\left(1-t^{*}\right) r_{b^{*}}^{*}-r_{b^{*}}>0 \\
\phi_{t^{*}} & =-r^{*}<0 \\
\phi_{p} & =\left(1-t^{*}\right) r_{p}^{*}-r_{p} .
\end{aligned}
$$

Note that $\phi_{p}$ may be positive or negative, depending on how a change in $p$ affects the rental rates of K-capital in the two countries.

Making use of the partial derivatives given in (17a) to (17c), and when given $t^{*}$ and $p$, the equilibrium condition (16a) can be illustrated by schedule $\phi \phi$ in Figure 1. Its slope is equal to

$$
\left.S_{\phi} \equiv \frac{\mathrm{d} b^{*}}{\mathrm{~d} k}\right|_{\phi \phi}=-\frac{\phi_{k}}{\phi_{b^{*}}}>0 .
$$


Equation (18) means that schedule $\phi \phi$ is positively sloped. The reason is that by Lemma 1 , an increase in $k$ will raise $r$, the rental rate of K-capital, while an increase in $b^{*}$ will lower $r$. Therefore, to restore equilibrium in terms of movement of the type-K capital, an increase in $k$ requires a rise in $b^{*}$.

We now turn to function $\theta$. Differentiating both sides of equation (15b) and rearranging the terms, we get

$$
\begin{aligned}
\theta_{k} & =(1-\tau) \gamma_{k}-\gamma_{k}^{*}>0 \\
\theta_{b^{*}} & =(1-\tau) \gamma_{b^{*}}-\gamma_{b^{*}}^{*}<0 \\
\theta_{\tau} & =-\gamma<0 \\
\theta_{p} & =(1-\tau) \gamma_{p}-\gamma_{p}^{*} .
\end{aligned}
$$

With given $p$ and $\tau$, function $\theta$ is illustrated by curve $\theta \theta$ in Figure 1 . Its slope is equal to

$$
\left.S_{\theta} \equiv \frac{\mathrm{d} b^{*}}{\mathrm{~d} k}\right|_{\theta \theta}=-\frac{\theta_{k}}{\theta_{b^{*}}}>0
$$

Define the following matrix:

$$
\mathbf{A}=\left[\begin{array}{cc}
\phi_{k} & \phi_{b^{*}} \\
\theta_{k} & \theta_{b^{*}}
\end{array}\right]
$$

Define $D \equiv \phi_{k} \theta_{b^{*}}-\phi_{b^{*}} \theta_{k}$ as the determinant of $\mathbf{A}$. In Figure 1, point $\mathrm{E}$ is a point of intersection between schedules $\phi \phi$ and $\theta \theta$, and thus represents an equilibrium with movement of both types of capital under free trade. To allow the comparative static analysis introduced below, we assume that such an equilibrium is unique.

To find constraints on the slopes of the two schedules, we analyze the stability of an equilibrium described by an intersection between the two schedules. Assume that the two types of capital move according to the following equations:

$$
\begin{aligned}
\dot{k} & =\phi\left(k, b^{*}, t^{*} ; \bar{p}\right) \\
\dot{b} & =\theta\left(k, b^{*}, \tau ; \bar{p}\right),
\end{aligned}
$$

where a dot above a variable represents the time derivative of the variable. These two conditions mean that capital is attracted from a place where its after-tax income is lower to a place where its after-tax income is higher. 
Lemma 2 Given the adjustment conditions (21a) and (21b), an equilibrium as described by (16a) and (16b) is stable if $A$ is negative definite.

The stability condition as described by Lemma 2 is a standard one. Its proof is omitted. The lemma implies that $\phi_{k}<0, \theta_{b^{*}}<0$, and $D>0$. The sign of $D$ in turn implies that

$$
-\frac{\phi_{k}}{\phi_{b^{*}}}>-\frac{\theta_{k}}{\theta_{b^{*}}},
$$

or $S_{\phi}>S_{\theta}$. In other words, in Figure 1, schedule $\phi \phi$ is steeper than schedule $\theta \theta$ at the equilibrium point. This is the case shown.

\section{Investment Liberalization}

Refer back to the equilibrium as described by the system of equations (16a) and (16b). Differentiate these two equations and rearrange the terms to give

$$
\mathbf{A}\left[\begin{array}{c}
\mathrm{d} k \\
\mathrm{~d} b
\end{array}\right]=\left[\begin{array}{c}
r^{*} \mathrm{~d} t^{*} \\
\gamma \mathrm{d} \tau
\end{array}\right] .
$$

Using Cramer's rule, we have

$$
\begin{aligned}
\mathrm{d} k & =\frac{\theta_{b^{*}} r^{*} \mathrm{~d} t^{*}-\phi_{b^{*}} \gamma \mathrm{d} \tau}{D} \\
\mathrm{~d} b^{*} & =\frac{\gamma \phi_{k} \mathrm{~d} \tau-\theta_{k} r^{*} \mathrm{~d} t^{*}}{D} .
\end{aligned}
$$

\subsection{Unilateral Investment Liberalization}

To determine the effects of investment liberalization on income distribution, let us consider first the case of unilateral investment liberalization: home slightly reduces its restriction on the inflow of foreign B-capital while the foreign investment policy is unchanged, i.e., there is a small drop in the value of $\tau$ while $t^{*}$ is fixed. The impacts on the movement of the two types of capital can be obtained from (23a) and (23b) by setting $\mathrm{d} t^{*}=0$ and rearranging the terms:

$$
\begin{aligned}
\frac{\partial k}{\partial \tau} & =-\frac{\phi_{b^{*}} \gamma}{D}=-\frac{\left[\left(1-t^{*}\right) r_{b^{*}}^{*}-r_{b^{*}}\right] \gamma}{D}<0 \\
\frac{\partial b^{*}}{\partial \tau} & =\frac{\phi_{k} \gamma}{D}=\frac{\left[\left(1-t^{*}\right) r_{k}^{*}-r_{k}\right] \gamma}{D}<0 .
\end{aligned}
$$


Equations (24a) and (24b) suggest that a more liberal investment policy by the home government on the inflow of B-capital encourages not only the inflow of foreign B-capital but also the outflow of domestic K-capital. The intuition behind this result is simple. Liberalizing the inflow of foreign Bcapital directly encourages the inflow of that capital, but that will tend to draw labor from the domestic K-sector. This lowers the marginal product of K-capital in that sector. However, just the opposite occurs in the foreign country: a movement of foreign labor from the B-sector to the K-sector, raising the marginal product of K-capital. Thus more domestic K-capital is encouraged to flow from home to foreign.

Proposition 1 A small decrease in $\tau$ encourages more movement of both types of capital.

The above result can be illustrated in Figure 2. From its definition as given by equation (15a), function $\phi$ is independent of $\tau$. On the other hand, function $\theta$ as given by equation (15b) means that a decrease in $\tau$ shifts schedule $\phi \phi$ in Figure 2 upward. In the diagram, schedules $\phi \phi$ and $\theta \theta$ correspond to the initial value of $\tau$, with the equilibrium point at E. Liberalization of inflow of foreign B-capital shifts schedule $\theta \theta$ upward to $\theta^{\prime} \theta^{\prime}$, which intersects unchanged schedule $\phi \phi$ at point $\mathrm{E}^{\prime}$. The diagram confirms that equilibrium values of $k$ and $b^{*}$ increase.

How may this policy affect factor prices? This question can be answered by evaluating the following derivatives and expressions:

$$
\begin{aligned}
\frac{\mathrm{d} r}{\mathrm{~d} \tau} & =r_{k} \frac{\partial k}{\partial \tau}+r_{b^{*}} \frac{\partial b^{*}}{\partial \tau} \\
\frac{\mathrm{d} \gamma}{\mathrm{d} \tau} & =\gamma_{k} \frac{\partial k}{\partial \tau}+\gamma_{b^{*}} \frac{\partial b^{*}}{\partial \tau} \\
\frac{\mathrm{d} w}{\mathrm{~d} \tau} & =w_{k} \frac{\partial k}{\partial \tau}+w_{b^{*}} \frac{\partial b^{*}}{\partial \tau}
\end{aligned}
$$

The effects of unilateral investment liberalization on factor prices can be evaluated by substituting the values of the derivatives given earlier into the right-hand sides of conditions (25a) to (25c). Before we do that, we can first look at the right-hand sides of these conditions, and note that, based on earlier analysis, the two terms on the right-hand side always have different signs. For example, in equation (25a), while the derivatives of $k$ and $b^{*}$ with respect to $\tau$ is negative, $r_{k}>0$ and $r_{b^{*}}<0$. Therefore the signs of the effects 
on a change in $\tau$ on factor prices are in general ambiguous. We can, however, get the results stated in the following two propositions:

Proposition $2 A$ small reduction in $\tau$ either increases the rental rates of both types of capital and decreases the wage rate, or decreases the two rental rates and increases the wage rate.

Proof. This proposition can be proved by substituting condition (8) into (25a) to (25c). First, using (8), (25b) reduces to

$$
\frac{\mathrm{d} \gamma}{\mathrm{d} \tau}=\frac{\gamma_{b^{*}}}{r_{b^{*}}}\left[r_{k} \frac{\partial k}{\partial \tau}+r_{b^{*}} \frac{\partial b^{*}}{\partial \tau}\right]=\frac{\gamma_{b^{*}}}{r_{b^{*}}} \frac{\mathrm{d} r}{\mathrm{~d} \tau} .
$$

Since $\gamma_{b^{*}}$ and $r_{b^{*}}$ are both negative, (26) implies that as $\tau$ is changed, $\gamma$ and $r$ will move in the same direction.

Similarly, using (8), (25c) reduces to

$$
\frac{\mathrm{d} w}{\mathrm{~d} \tau}=\frac{w_{b^{*}}}{r_{b^{*}}}\left[r_{k} \frac{\partial k}{\partial \tau}+r_{b^{*}} \frac{\partial b^{*}}{\partial \tau}\right]=\frac{w_{b^{*}}}{r_{b^{*}}} \frac{\mathrm{d} r}{\mathrm{~d} \tau} .
$$

Because $w_{b^{*}}>0$ and $r_{b^{*}}<0,(27)$ implies that $w$ and $r$ are affected in opposite ways by a change in $\tau$.

This proposition implies that a unilateral investment liberalization will benefit some factor owners and will hurt some others. The next question is who will benefit. To answer this question, let us consider the following condition:

$$
r_{b^{*}}^{*} r_{k}>r_{k}^{*} r_{b^{*}}
$$

To interpret condition (A), rearrange the terms, noting that $r_{b^{*}}<0$ and $r_{b^{*}}^{*}>0$, to give

$$
-\frac{r_{k}}{r_{b^{*}}}>-\frac{r_{k}^{*}}{r_{b^{*}}^{*}}
$$

Note that both sides of the inequality in $\left(\mathrm{A}^{\prime}\right)$ are positive. Condition $(\mathrm{A})$ or $\left(\mathrm{A}^{\prime}\right)$ means that home rental rate of $\mathrm{K}$-capital is relatively more responsive to K-capital movement, or that foreign rental rate of K-capital is more responsive to B-capital movement. 
Given Lemma 1, and if this lemma also holds for the foreign economy, condition $(\mathrm{A})$ is equivalent to

$$
-\frac{\gamma_{k}}{\gamma_{b^{*}}}>-\frac{\gamma_{k}^{*}}{\gamma_{b^{*}}^{*}}
$$

Proposition 3 A small unilateral investment liberalization will improve the rental rates of both types of capital and will lower the wage rate if and only if condition (A) is satisfied.

Proof. We first look at the effects on the rental rate of K-capital. Substitute conditions (24a) and (24b) into (25a) and rearrange terms to give

$$
\begin{aligned}
\frac{\mathrm{d} r}{\mathrm{~d} \tau} & =-\frac{r_{k}\left[\left(1-t^{*}\right) r_{b^{*}}^{*}-r_{b^{*}}\right] \gamma}{D}+\frac{r_{b^{*}}\left[\left(1-t^{*}\right) r_{k}^{*}-r_{k}\right] \gamma}{D} \\
& =\frac{\left(1-t^{*}\right)\left(r_{b^{*}} r_{k}^{*}-r_{k} r_{b^{*}}^{*}\right) \gamma}{D}
\end{aligned}
$$

which is negative if and only if condition (A) holds. The rest of the proof follows Proposition 2.

Proposition 3 implies that with the unilateral investment liberalization there are some factor owners who will benefit and some other factor owners who will lose.

We now examine how unilateral investment liberalization may affect commodity trade. Totally differentiate the export supply of good 1 to give

$$
\frac{\mathrm{d} E}{\mathrm{~d} \tau}=\frac{\partial E}{\partial k} \frac{\mathrm{d} k}{\mathrm{~d} \tau}+\frac{\partial E}{\partial b^{*}} \frac{\mathrm{d} b^{*}}{\mathrm{~d} \tau}+\frac{\partial E}{\partial \tau} .
$$

On the right-hand side of equation (28), the first two terms are the indirect effects of the policy through capital movement and the third term is the direct effect, which is negative. The first indirect effect has an ambiguous sign while the second one is positive. So the effect of investment liberalization on commodity trade is ambiguous. In the special cases in which the levels of movements of both types of capital are sufficiently small, then, as shown earlier, $E_{k}<0$ and $E_{\tau}$ is small, implying that $\mathrm{d} E / \mathrm{d} \tau$ in $(28)$ is positive. In other words, in these cases a drop in $\tau$ will also decrease home's export of $\operatorname{good} 1$. 
Proposition 4 A small decrease in $\tau$ lowers the home country's export of good 1 if the initial inflow of foreign B-capital is sufficiently small.

We now examine the quantitative relationship between commodity trade and capital movement. ${ }^{11}$ Mundell (1957) analyzes how a change in the tariff imposed by one country may affect the level of factor movement, which in turn affects the volume of trade. In this paper, we examine the effects of a change in the income tax imposed by a country. By Proposition 1, a small decrease in $\tau$ encourages the movements of both types of capital. ${ }^{12}$ This proposition and Proposition 4 can be combined to give the following:

Proposition 5 If the initial B-capital movement is small, movement of both types of capital diminishes commodity trade.

Using the terminology in Wong (1986), we say that capital movement diminishes commodity trade. Because we have not analyzed how commodity trade may affect capital movement, it is not clear whether they are substitutes. ${ }^{13}$

\subsection{A Graphical Interpretation}

We now introduce a simple graphical apparatus to interpret the effects of the investment liberalization policy on income distribution. This apparatus is convenient and will be used again later in this paper.

Using equations (7d) to (7i), the three domestic factor prices can be expressed as functions of the movement of the two types of capital. In Figure 3 , we can show contours showing combinations of $k$ and $b^{*}$ that lead to the same value of a factor price. For example, let us consider first contours for the rental rate of K-capital, $r$. In Figure 2, one of these contours is shown

\footnotetext{
${ }^{11}$ Wong (1986) distinguishes between two types of the relationship between commodity trade and factor movement: price equalization and quantitative relationship, with the former focusing on whether one or both of them can lead to the world's integrated equilibrium, and the latter on how a change in the level of one may lead to a change in the level of the other. In the present paper, we look only at the quantitative relationship between them.

${ }^{12}$ Markusen (1983) analyzes the effects of capital movement on commodity trade in several models. In these models, the change in capital movement is given exogenously.

${ }^{13}$ Wong (1986) defines substitutability between commodity trade and factor movement if one of them diminishes the other and vice versa.
} 
and labeled $f f$. This contour passes point $\mathrm{E}$, the initial equilibrium point, and represents different values of $k$ and $b^{*}$ that will yield the value of $r$ at the initial equilibrium level. The slope of contour $f f$ is equal to

$$
\left.S_{r} \equiv \frac{\mathrm{d} b^{*}}{\mathrm{~d} k}\right|_{r r}=-\frac{r_{k}}{r_{b^{*}}}>0
$$

where the signs of $r_{k}$ and $r_{b^{*}}$ come from conditions (7e) and (7h). Thus, contour $f f$ is positively sloped. Furthermore, points on the left- (right-)hand side of the schedule represent lower (higher) values of $r$.

The same analysis can be applied to the other two factor prices, $\gamma$ and $w$. The slope of a $\gamma$-contour and that of a $w$-contour are given by

$$
\begin{aligned}
S_{\gamma} & \left.\equiv \frac{\mathrm{d} b^{*}}{\mathrm{~d} k}\right|_{\gamma \gamma}=-\frac{\gamma_{k}}{\gamma_{b^{*}}}>0 \\
S_{w} & \left.\equiv \frac{\mathrm{d} b^{*}}{\mathrm{~d} k}\right|_{w w}=-\frac{w_{k}}{w_{b^{*}}}>0,
\end{aligned}
$$

where the derivatives are given by $(7 \mathrm{f}),(7 \mathrm{i}),(7 \mathrm{~d})$, and $(7 \mathrm{~g})$. It is interesting to note that the contours for all three factor prices are positively sloped. This is due to the fact that the two types of capital movement have opposite effects on each factor price. Points on the left- (right-)hand of a contour for $\gamma$ represents lower (higher) values of $\gamma$. Similarly, points on the left- (right-) hand of a contour for $w$ represents higher (lower) values of $w$. From Lemma 1 , we have

Lemma 3: At the initial equilibrium point, $S_{r}=S_{w}=S_{\gamma}$.

Because of Lemma 3, schedule $f f$ in Figure 2 can be used to represent all three factor price schedules passing through the initial equilibrium point. The lemma also confirms Proposition 3 that because the new equilibrium point must be on either the left-hand side or the right-hand side of the three schedules, a small decrease in $\tau$ must change $r$ and $\gamma$ in the same direction and $w$ in the opposite direction. The following lemma helps determine how the factor prices may change:

Lemma 4: (a) If condition (A) holds, then $S_{r}=S_{w}=S_{\gamma}>S_{\phi}>S_{\theta}$; or (b) if condition (A) does not hold, then $S_{\phi}>S_{\theta}>S_{r}=S_{w}=S_{\gamma}$, where all slopes are evaluated at the initial equilibrium point. 
Proof. From Lemma 2, we know that $S_{\phi}>S_{\theta}$. We then consider the difference between $S_{r}$ and $S_{\phi}$ :

$$
S_{r}-S_{\phi}=\frac{\left(1-t^{*}\right) r_{k}^{*}-r_{k}}{\left(1-t^{*}\right) r_{b^{8}}^{*}-r_{b^{*}}}-\frac{r_{k}}{r_{b^{*}}}=\frac{\left(1-t^{*}\right)\left(r_{k}^{*} r_{b^{*}}-r_{b^{*}}^{*} r_{k}\right)}{r_{b^{*}}\left[\left(1-t^{*}\right) r_{b^{*}}^{*}-r_{b^{*}}\right]},
$$

which is positive if condition (A) is satisfied, noting that $r_{b^{*}}<0$ and $r_{b^{*}}^{*}>0$. We next compare $S_{\gamma}$ with $S_{\theta}$ :

$$
S_{\theta}-S_{\gamma}=\frac{\gamma_{k}}{\gamma_{b^{*}}}-\frac{(1-\tau) \gamma_{k}-\gamma_{k}^{*}}{(1-\tau) \gamma_{b^{*}}-\gamma_{b^{*}}^{*}}=\frac{\gamma_{b^{*}} \gamma_{k}^{*}-\gamma_{k} \gamma_{b^{*}}^{*}}{\gamma_{b^{*}}\left[(1-\tau) \gamma_{b^{*}}-\gamma_{b^{*}}^{*}\right]},
$$

which is positive if condition $\left(\mathrm{A}^{\prime \prime}\right)$ is violated, noting that $\gamma_{b^{*}}<0$ and $\gamma_{b^{*}}^{*}>0$. Note also that condition $(\mathrm{A})$ is equivalent to $\left(\mathrm{A}^{\prime \prime}\right)$. Using Lemma 3, we have Lemma 4.

Lemma 4 implies that in the small region close to the initial equilibrium point, schedule $f f$ for the three factor prices will not be in the region bounded by schedules $\phi \phi$ and $\theta \theta$. Lemma 4 also confirms Proposition 4 , because, as we showed earlier that after a small unilateral investment liberalization the new equilibrium point, $\mathrm{E}^{\prime}$, must be higher than point $\mathrm{E}$ and on schedule $\phi \phi$.

\subsection{Multilateral Investment Liberalization}

We now turn to multilateral investment liberalization and determine its impacts on factor prices. Suppose that home and foreign agree to lower their income taxes by the same proportion. In other words, we assume that

$$
\frac{\mathrm{d} \tau}{\tau}=\frac{\mathrm{d} t^{*}}{t^{*}}<0
$$

Alternatively, we have

$$
\mathrm{d} t^{*}=\sigma \mathrm{d} \tau<0,
$$

where $\sigma \equiv t^{*} / \tau$. The value of $\sigma$ depends on the initial income taxes in the two countries. In particular, $\sigma \rightarrow 0$ if $t^{*} \rightarrow 0$, or $\sigma \rightarrow \infty$ if $\tau \rightarrow 0$. Substitute (32) into (23a) and (23b) to yield

$$
\begin{aligned}
\frac{\mathrm{d} k}{\mathrm{~d} \tau} & =\frac{\theta_{b^{*}} r^{*} \sigma-\phi_{b^{*}} \gamma}{D}<0 \\
\frac{\mathrm{d} b^{*}}{\mathrm{~d} \tau} & =\frac{\gamma \phi_{k}-\theta_{k} r^{*} \sigma}{D}<0 .
\end{aligned}
$$


The signs of the effects of multilateral investment liberalization given in (33a) and $(33 \mathrm{~b})$ come from the properties of functions $\phi$ and $\theta$ derived earlier. These two equations show that liberalization of direct investment by both countries will encourage the movement of both types of capital. The magnitudes of the effects on the movement of each type of capital depends on, among other things, the initial income tax ratio, $\sigma$.

Proposition 6 Multilateral investment liberalization encourages the movement of both types of capital.

Proposition 6 is not surprising. By Proposition 1, a unilateral investment liberalization by the home country benefits the movement of both types of capital. We expect that Proposition 1 can be applied to a unilateral investment liberalization by the foreign country, which means that unilateral investment liberalization policies by the countries reinforce each other on the movement of both types of capital. Thus if both countries agree to reduce their restriction on investment from the other countries, movements of both types of capital benefit.

The changes in the movement of both types of capital can be illustrated in Figure 3. From the derivatives of functions $\phi$ and $\theta$, a small decrease in $\tau$ will shift schedule $\theta \theta$ upward while a small decrease in $t^{*}$ shifts schedule $\phi \phi$ to the right. The new equilibrium point, $\mathrm{E}^{\prime}$, must be in the region above the initial equilibrium point $\mathrm{E}$ and bounded by schedules $\phi \phi$ and $\theta \theta$.

The last result is very useful, because we can use the results derived earlier to determine the impacts of multilateral investment liberalization on income distribution. Applying Lemma 4, we have

Proposition 7 A small multilateral investment liberalization will improve the home rental rates of both types of capital and will lower the home wage rate if and only if condition (A) is satisfied.

Based on Proposition 7, we can conclude that multilateral investment liberalization can win the unanimous support from all owners of different factors, as long as factor owners care only about their factor service incomes. 


\section{Investment Liberalization with Monopoly Power in Trade}

So far, our analysis is limited to the cases in which commodity prices faced by the countries are not affected by the movement of capital. We found that either unilateral or multilateral investment liberalization will benefit some factor owners but hurt some other factor owners. The next question is whether by relaxing this assumption we can find a Pareto improving (for the home country) multilateral investment liberalization.

We now determine how the world price ratio is determined endogenously. To do that, we have to derive the features of the foreign country more explicitly. With given domestic price ratio $p^{*}$ and the amounts of the two types of capital, $\bar{K}^{*}+k$ and $\bar{B}^{*}-b^{*}$, the foreign GDP function can be denoted by $g^{*}\left(p^{*}, \bar{K}^{*}+k, \bar{B}^{*}-b^{*}\right)$, where the given labor endowment is not shown for simplicity. The foreign national income is defined as

$$
Y^{*}\left(p^{*}, k, b^{*}, \tau, t^{*}\right)=g^{*}\left(p^{*}, \bar{K}^{*}+k, \bar{B}^{*}-b^{*}\right)+(1-\tau) \gamma b^{*}-\left(1-t^{*}\right) r^{*} k .
$$

The derivatives of this function are given as

$$
\begin{aligned}
Y_{p^{*}}^{*} & =Q_{1}^{*}+(1-\tau) \gamma_{p^{*}} b^{*}-\left(1-t^{*}\right) r_{p^{*}}^{*} k \\
Y_{k}^{*} & =t^{*} r^{*}+(1-\tau) \gamma_{k}^{*} b^{*}-\left(1-t^{*}\right) r_{k}^{*} k>0 \\
Y_{b^{*}}^{*} & =(1-\tau) \gamma_{b^{*}} b^{*}-\left(1-t^{*}\right) r_{b^{*}}^{*} k<0 \\
Y_{\tau}^{*} & =-\gamma b^{*}<0 \\
Y_{t^{*}}^{*} & =r^{*} k>0 .
\end{aligned}
$$

Note that the sign of $Y_{p^{*}}^{*}$ is ambiguous, because while the production effect is positive, an increase in $p$ lowers the income of foreign capital working in the home country but raises the payment to home capital working locally. The foreign consumption demand can be denote by $C_{1}^{*}\left(p^{*}, Y^{*}\left(p^{*}, k, b^{*}, \tau, t^{*}\right)\right)$. Define $m^{*} \equiv \partial C_{1}^{*} / \partial Y^{*}$, where $m^{*} p^{*}$ is the foreign propensity to consume good 1. Assuming that both goods are normal, $1>m^{*} p^{*}>0$. The foreign export supply function of good 1 can now be defined as $E^{*}\left(p^{*}, k, b^{*}, \tau, t^{*}\right) \equiv$ $Q_{1}^{*}\left(p^{*}, k, b^{*}\right)-C_{1}^{*}\left(p^{*}, Y^{*}\left(p^{*}, k, b^{*}, \tau, t^{*}\right)\right)$. The following derivatives of the for- 
eign export supply function can be derived:

$$
\begin{aligned}
E_{p^{*}}^{*} & =\frac{\partial Q_{1}^{*}}{\partial p^{*}}-\left[\frac{\partial C_{1}^{*}}{\partial p^{*}}+m^{*} Y_{p^{*}}^{*}\right] \\
E_{k}^{*} & =Q_{1 k}^{*}-m^{*} Y_{k}^{*} \\
E_{b^{*}}^{*} & =Q_{1 b^{*}}^{*}-m^{*} Y_{b^{*}}^{*}>0 \\
E_{\tau}^{*} & =-m^{*} Y_{\tau}^{*}>0 \\
E_{t^{*}}^{*} & =-m^{*} Y_{t^{*}}^{*}<0 .
\end{aligned}
$$

The signs of $E_{p^{*}}^{*}$ and $E_{k}^{*}$ are in general ambiguous. If the foreign offer curve is positively sloped, then $E_{p^{*}}^{*}>0$. If the tax rate $t^{*}$ and the movements of both types of capital are small, then $E_{k}^{*}>0$.

The equilibrium of the good-1 market in the world is given by ${ }^{14}$

$$
E\left(p, k, b^{*}, \tau, t^{*}\right)+E^{*}\left(p, k, b^{*}, \tau, t^{*}\right)=0,
$$

where the equilibrium condition $p=p^{*}$ has been used. Assuming a unique free-trade equilibrium, the equilibrium world relative price of good 1 can be expressed as a function of other variables:

$$
p=p\left(k, b^{*}, \tau, t^{*}\right)
$$

The partial derivatives of function $p$ can be obtained by totally differentiating (34) and rearranging terms to give

$$
\begin{aligned}
p_{k} & =-\frac{E_{k}+E_{k}^{*}}{\Theta} \\
p_{b^{*}} & =-\frac{E_{b^{*}}+E_{b^{*}}^{*}}{\Theta} \\
p_{\tau} & =-\frac{E_{\tau}+E_{\tau}^{*}}{\Theta} \\
p_{t^{*}} & =-\frac{E_{t^{*}}+E_{t^{*}}^{*}}{\Theta},
\end{aligned}
$$

where $\Theta \equiv E_{p}+E_{p^{*}}^{*}$. To have a free-trade equilibrium stable in a Walrasian sense, we assume that $\Theta>0$. The general principle for a change in $p$ is that

\footnotetext{
${ }^{14}$ Note that if the world capital markets and the world good-1 market are in equilibrium, by the Walras Law, so is the world good-2 market.
} 
if a change in a variable such as $k$ leads to an excess supply of good 1 at the initial price level, then $p$ will drop. However, the signs of the derivatives in (36a) to (36d) are generally ambiguous, because the numerators in these expressions have ambiguous signs.

To simplify the following analysis, let us make one additional assumption: Both countries have identical and homothetic preferences. Since under free trade the two countries are facing the same relative commodity price, $m=$ $m^{*}$. Using the above analysis, $E_{\tau}+E_{\tau}^{*}=E_{t^{*}}+E_{t^{*}}^{*}=0$, which means that $p_{\tau}=$ $p_{t^{*}}=0$. This result is not surprising, because a change in either income tax, $\tau$ or $t^{*}$, is a redistribution of income between the countries. With identical and homothetic preferences, and when facing the same commodity prices, the decrease in the demand for good 1 by the country that faces a drop in income is matched by an increase in the demand for the good by the same amount by the other country. With production of the good independent of income taxes, the equilibrium commodity price ratio remains unchanged. As a result, condition (35) can be written as

$$
p=p\left(k, b^{*}\right) .
$$

When the commodity price ratio is determined endogenously, the techniques developed in previous sections for analyzing the effects of investment liberalization can be applied here although the analysis becomes more complicated. First, the equilibrium of capital movement under free trade can still be described by conditions (15a) and (15b), although both functions now depend not only on the capital movement and income taxes, but also on the relative price $p$. We can, however, substitute condition (37) into the functions and define two new functions:

$$
\begin{aligned}
\tilde{\phi}\left(k, b^{*}, t^{*}\right) & \equiv \phi\left(k, b^{*}, t^{*}, p\left(k, b^{*}\right)\right) \\
\tilde{\theta}\left(k, b^{*}, \tau\right) & \equiv \theta\left(k, b^{*}, \tau, p\left(k, b^{*}\right)\right) .
\end{aligned}
$$

The derivatives of these two functions, which can be determined in the usual way, are equal to:

$$
\begin{aligned}
\tilde{\phi}_{k} & =\phi_{k}+\phi_{p} p_{k} \\
\tilde{\phi}_{b^{*}} & =\phi_{b^{*}}+\phi_{p} p_{b^{*}} \\
\tilde{\theta}_{k} & =\theta_{k}+\theta_{p} p_{k} \\
\tilde{\theta}_{b^{*}} & =\theta_{b^{*}}+\theta_{p} p_{b^{*}} .
\end{aligned}
$$


The partial derivatives in general have ambiguous signs.

When given the policy parameters $\tau$ and $t^{*}$, functions $\tilde{\phi}\left(k, b^{*}, t^{*}\right)$ and $\tilde{\theta}\left(k, b^{*}, \tau\right)$ can be illustrated in Figure 4 by schedules $\tilde{\phi} \tilde{\phi}$ and $\tilde{\theta} \tilde{\theta}$. The slopes of the schedules are equal to

$$
\begin{gathered}
\left.\tilde{S}_{\phi} \equiv \frac{\mathrm{d} b^{*}}{\mathrm{~d} k}\right|_{\tilde{\phi} \tilde{\phi}}=-\frac{\tilde{\phi}_{k}}{\tilde{\phi}_{b^{*}}}>0 . \\
\left.\tilde{S}_{\theta} \equiv \frac{\mathrm{d} b^{*}}{\mathrm{~d} k}\right|_{\tilde{\theta} \tilde{\theta}}=-\frac{\tilde{\theta}_{k}}{\tilde{\theta}_{b^{*}}}>0 .
\end{gathered}
$$

Because the derivatives of the functions have ambiguous signs, the two schedules may be positively or negatively sloped. If, however, the two functions are not too sensitive to the commodity price ratio, then the derivatives are approximately the same as the corresponding ones derived in earlier sections with $p$ kept constant. As a result, both schedules are positively sloped, the case shown in Figure 4 and assumed in the rest of this paper. Again for a stable equilibrium, we assume that schedule $\tilde{\phi} \tilde{\phi}$ is steeper than schedule $\tilde{\theta} \tilde{\theta}$, i.e., $\tilde{S}_{\phi}>\tilde{S}_{\theta}$.

If both countries liberalize investment from the other country, movement of both types of capital will be encouraged. Graphically, schedule $\tilde{\phi} \tilde{\phi}$ shifts to the right while schedule $\tilde{\theta} \tilde{\theta}$ shifts up. The new equilibrium point $\mathrm{E}^{\prime}$ is above point $\mathrm{E}$ and is in the region bounded by schedules $\tilde{\phi} \tilde{\phi}$ and $\tilde{\theta} \tilde{\theta}$.

To determine how multilateral investment liberalization may affect income distribution in the home country, let us define the following reduced functions of the factor prices:

$$
\begin{aligned}
\tilde{w}\left(k, b^{*}\right) & \equiv w\left(k, b^{*}, p\left(k, b^{*}\right)\right) \\
\tilde{r}\left(k, b^{*}\right) & \equiv r\left(k, b^{*}, p\left(k, b^{*}\right)\right) \\
\tilde{\gamma}\left(k, b^{*}\right) & \equiv \gamma\left(k, b^{*}, p\left(k, b^{*}\right)\right) .
\end{aligned}
$$

These three reduced-form functions can be illustrated by contours in Figure 4 corresponding to different values of factor prices. For example, contour $\tilde{w} \tilde{w}$, which passes through the initial equilibrium point $\mathrm{E}$, represents different levels of movements of the two types of capital that produce the initial wage rate. Contours $\tilde{r} \tilde{r}$ and $\tilde{\gamma} \tilde{\gamma}$ can be interpreted in the same way. The slopes of 
these contours are equal to

$$
\begin{aligned}
\tilde{S}_{w} & =-\frac{\tilde{w}_{k}}{\tilde{w}_{b^{*}}}=-\frac{w_{k}+w_{p} p_{k}}{w_{b^{*}}+w_{p} p_{b^{*}}} \\
\tilde{S}_{r} & =-\frac{\tilde{r}_{k}}{\tilde{r}_{b^{*}}}=-\frac{r_{k}+r_{p} p_{k}}{r_{b^{*}}+r_{p} p_{b^{*}}} \\
\tilde{S}_{\gamma} & =-\frac{\tilde{\gamma}_{k}}{\tilde{\gamma}_{b^{*}}}=-\frac{\gamma_{k}+\gamma_{p} p_{k}}{\gamma_{b^{*}}+\gamma_{p} p_{b^{*}}} .
\end{aligned}
$$

In (39a) to (39c), the slopes of the three contours depend on, among other things, the values of $w_{p}, r_{p}$, and $\gamma_{p}$. As a result, the three contours may have different slopes at the initial equilibrium points and do not coincide. Furthermore, condition (A) is not sufficient to determine whether the three contours are steeper or less steep than schedules $\tilde{\phi} \tilde{\phi}$ and $\tilde{\theta} \tilde{\theta}$. In fact, it is possible that the three factor price contour through $\mathrm{E}$ can be steeper than schedule $\tilde{\theta} \tilde{\theta}$ while less steep than $\tilde{\phi} \tilde{\phi}$, a case shown in Figure 4.

We now turn to the following question: Does there exist a Pareto improving multilateral investment liberalization for the home country? To answer this question, let us refer to the case shown in Figure 4. In the case shown, the three contours for the factor prices divide the region above point $\mathrm{E}$ and bounded by schedules $\tilde{\phi} \tilde{\phi}$ and $\tilde{\theta} \tilde{\theta}$ into four subregions, which are labeled A, $\mathrm{B}, \mathrm{C}$, and D. In the presence of multilateral investment liberalization equilibrium, the new equilibrium point can be in each of these subregions, and being in a different subregion will have different impacts on the factor prices. Based on the analysis above, the impacts on the factor prices depending on where the new equilibrium point are described by the following table:

\begin{tabular}{llll} 
& $\Delta r$ & $\Delta \gamma$ & $\Delta w$ \\
\hline $\mathrm{A}$ & - & - & + \\
$\mathrm{B}$ & + & - & + \\
$\mathrm{C}$ & + & + & + \\
$\mathrm{D}$ & + & + & -
\end{tabular}

where a minus (plus) sign means that the variable decreases (increases) if the new equilibrium point shifts to that region as a result of investment liberalization by both countries.

The above table shows that in the case considered, at least some factor owners are better off. Therefore the investment liberalization agreement will 
receive at least some support. The interesting case is one in which the equilibrium point shifts to subregion $\mathrm{C}$, making all factor owners better off. This means that the home government can expect to get support from all factor owners, as long as they care only about how their income from factor services may change. Since it was shown that unilateral investment liberalization by either country shifts the equilibrium point up and along either schedule $\tilde{\phi} \tilde{\phi}$

or $\tilde{\theta} \tilde{\theta}$, Figure 4 further implies that in the present case liberalizing direct investment by either country will not yield Pareto improvement to the home country.

\section{Concluding Remarks}

As the WTO is paying more attention to trade related investment issues, it is expected that future trade talks will include liberalizing investment among countries. This paper examines how multilateral investment may affect income distribution and commodity trade.

We construct a model with sector-specific capital for the objective of this paper. This model has the advantage of allowing a general-equilibrium analysis of two-way capital movement and multilateral investment liberalization, and is used to capture the fact that international investment is embodied with sector-specific technology.

Our analysis shows that if investment liberalization has little effect on commodity prices in the world, then some factor owners in the home country will gain but some other factor owners will lose, whether the home country liberalizes investment unilaterally or both countries liberalize investment. If commodity prices are affected by capital movement, then it is possible that all factor owners in the home country gain from a multilateral investment liberalization.

The present analysis focuses mainly on income distribution in the absence of lumpsum compensation. One reason is that lumpsum compensation to fully compensate the loss of certain groups of people due to a trade policy is not common. An interesting extension of the present analysis is to see whether Pareto improving lumpsum compensation is available to a small open economy in the presence of a unilateral or multilateral investment liberalization. 


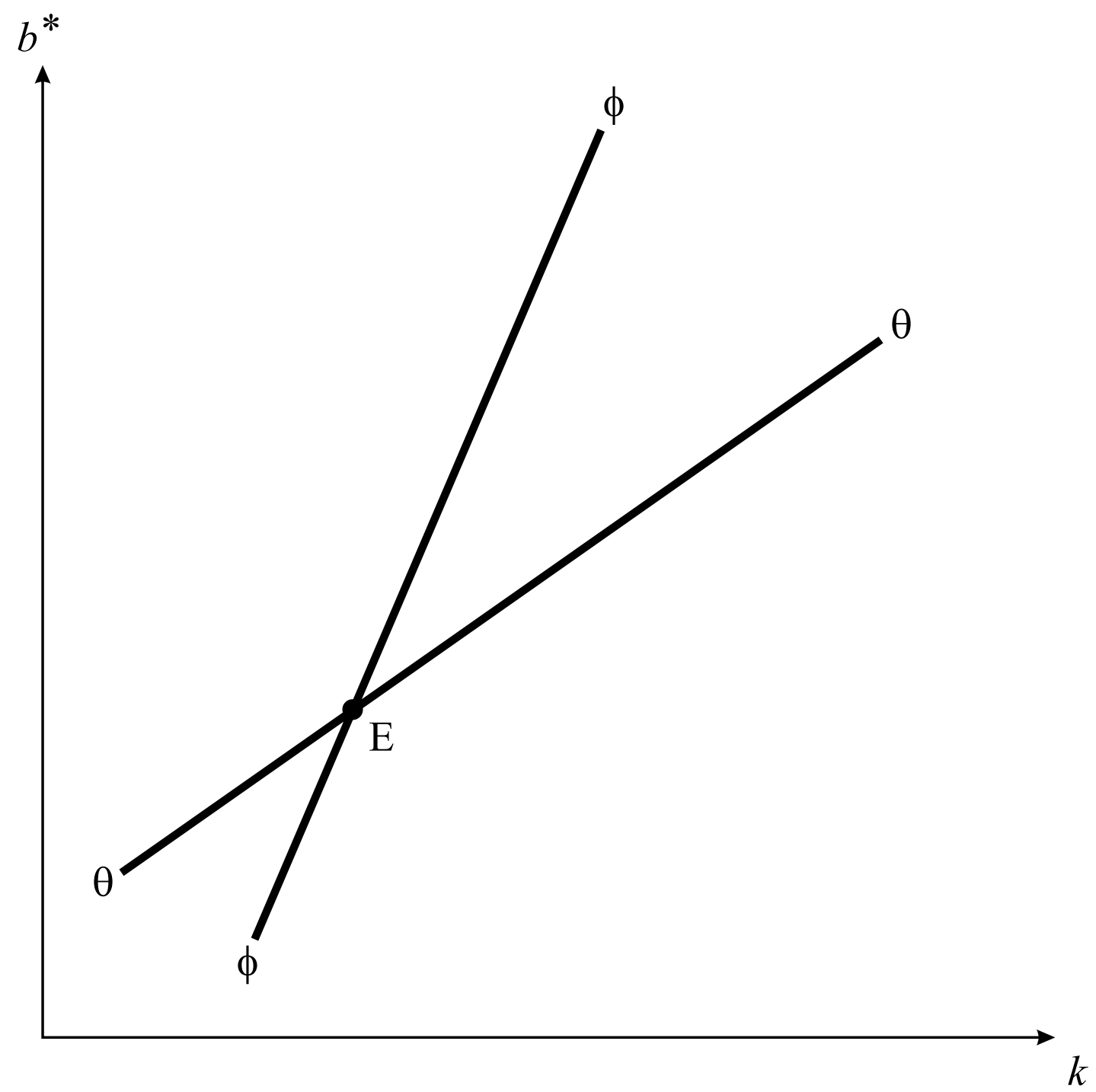

Figure 1 


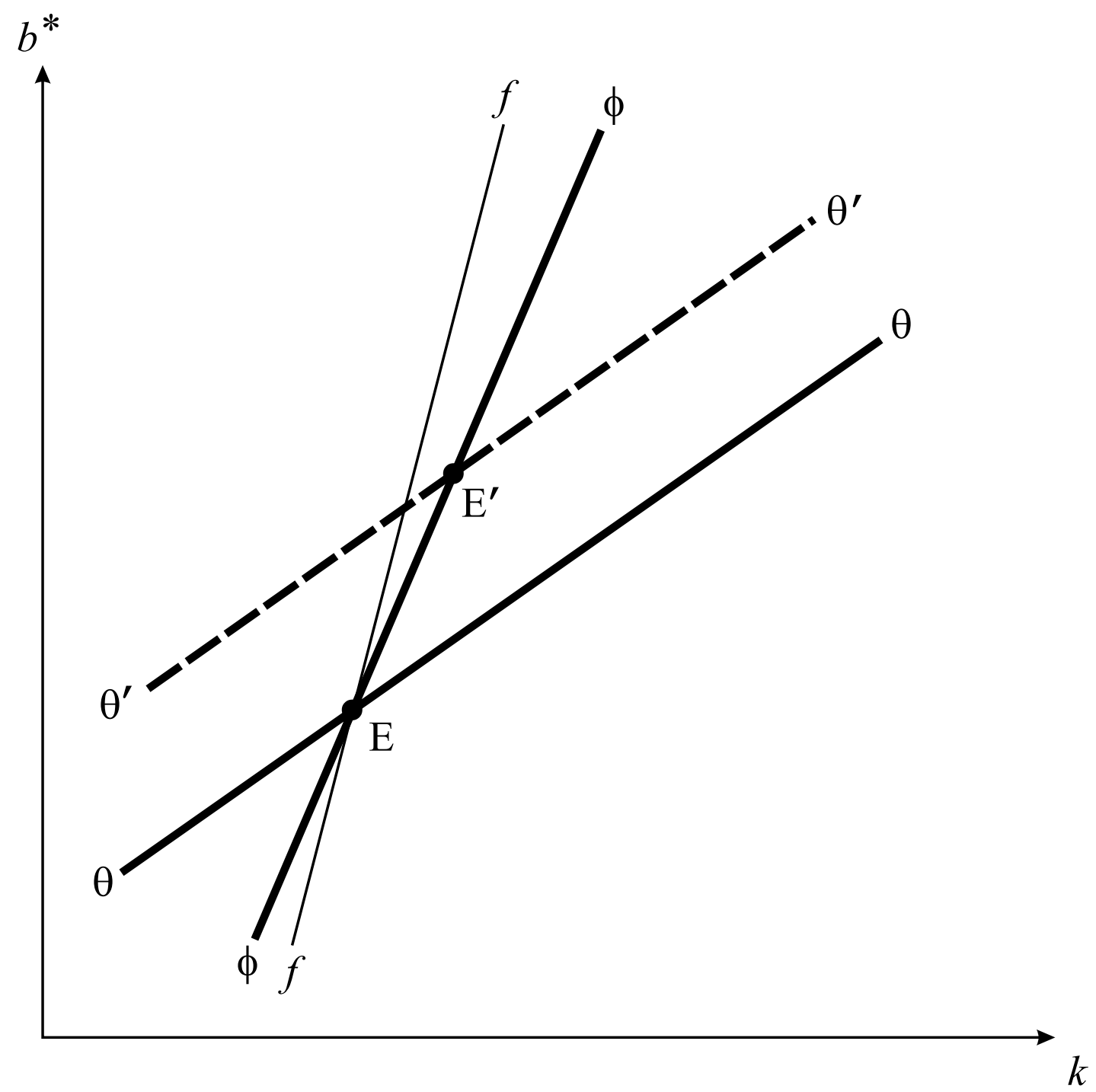

Figure 2 


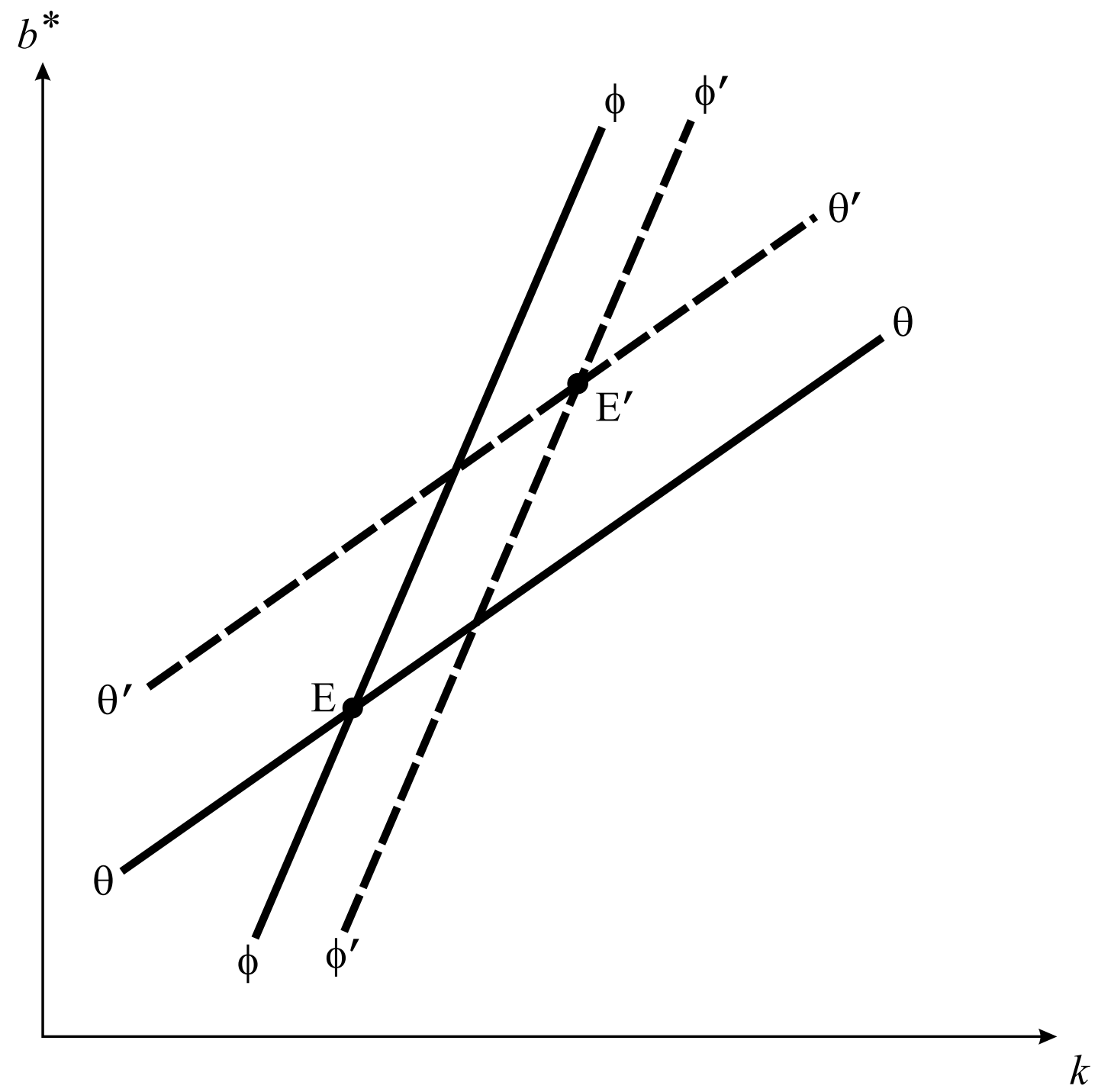

Figure 3 


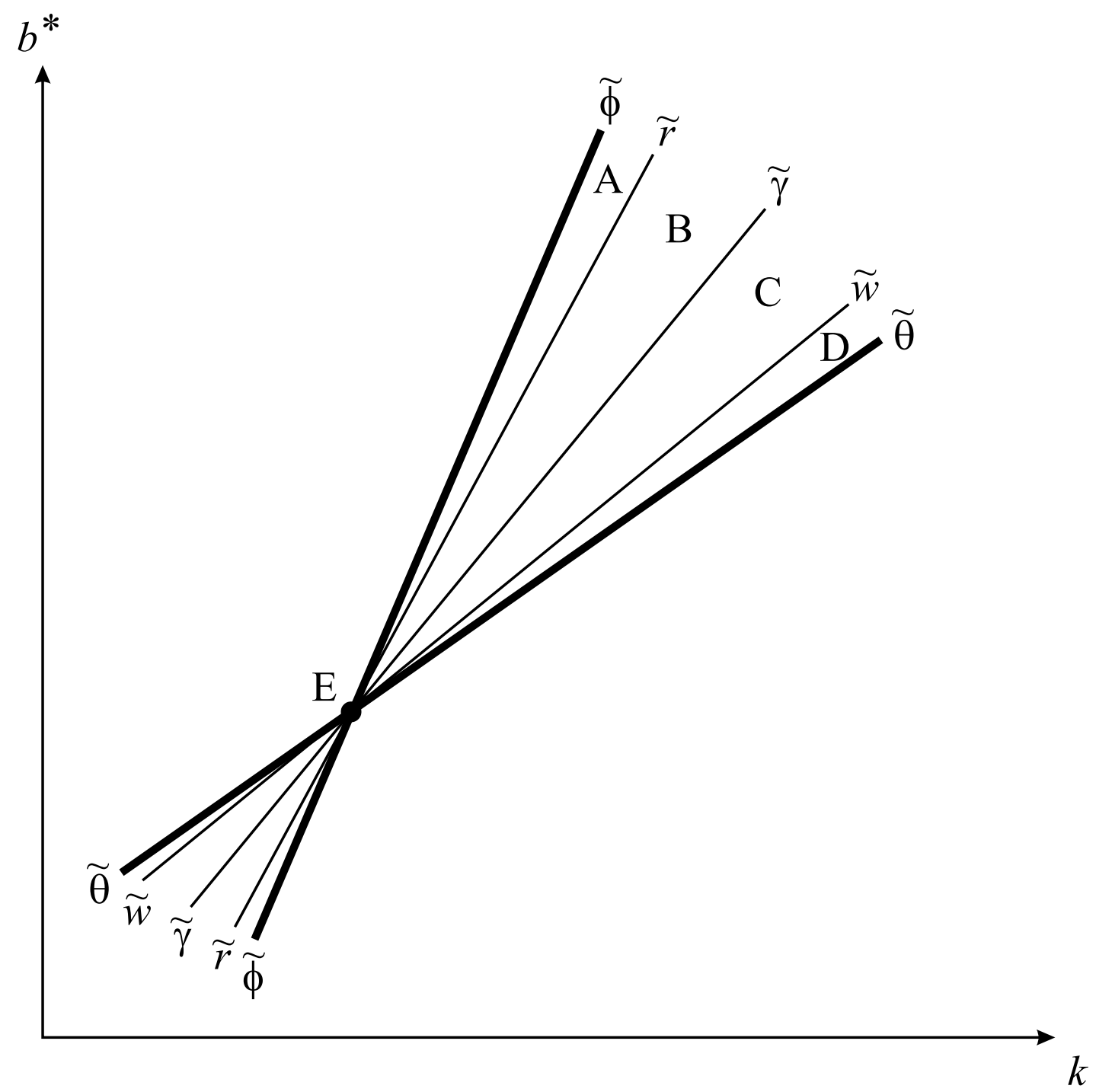

Figure 4 


\section{References}

[1] Batra, Raveendra N., and Rama Ramachandran (1980), "Multinational Firms and the Theory of International Trade and Investment," American Economic Review, 70: 278-290.

[2] Brecher, Richard A. and Ronald Findlay (1983), "Tariffs, Foreign Capital and National Welfare with Sector-Specific Factors," Journal of International Economics, 14: 277-288.

[3] Caves, Richard E. (1982), Multinational Enterprises and Economic Analysis. Cambridge: Cambridge University Press.

[4] Chan, Grace, and Kar-yiu Wong (1998), "Intraindustry Trade and Investment," mimeographed, University of Washington.

[5] Daly, Michael (1998), "Investment Incentives and the Multilateral Agreement on Investment," Journal of World Trade, 32: 5-26.

[6] Edwards, H. Robert, Jr. and Simon N. Lester (1997). "Towards a More Comprehensive World Trade Organization Agreement on Trade Related Investment Measures," Stanford Journal of International Law, 33: 169306.

[7] Graham, Edward (1996), "Direct Investment and Future Agenda of the World Trade Organization," in The World Trading System: Challenges Ahead, edited by Jeffrey J. Schott. Washington, D. C.: Institute for International Economics, 205-217.

[8] Jones, Ronald W. (1971). "A Three-Factor Model in Theory, Trade, and History," in J. N. Bhagwati, R. A. Mundell, R. W. Jones, and J. Vanek (eds.) Trade, Balance of Payments and Growth: Papers in International Economics in Honor of Charles P. Kindleberger. Amsterdam: NorthHolland, 3-21.

[9] Jones, Ronald W., J. Peter Neary, and Frances P. Ruane (1983), "TwoWay Capital Flows: Cross-Hauling in A Model of Foreign Investment," Journal of International Economics, 14: 357-366. 
[10] Markusen, James (1983), "Factor Movements and Commodity Trade as Complements," Journal of International Economics, 14: 341-356.

[11] Mundell, Robert (1957), "International Trade and Factor Mobility," American Economic Review, 36: 1557-1571.

[12] Srinivasan, T. N. (1983), "International Factor Movements, Commodity Trade and Commercial Policy in a Specific Factor Model," Journal of International Economics, 14: 215-230.

[13] Wong, Kar-yiu (1986), "Are International Trade and Factor Mobility Substitutes?" Journal of International Economics, 21: 25-43.

[14] Wong, Kar-yiu (1995), International Trade in Goods and Factor Mobility, Cambridge, Mass.: MIT Press. 